\title{
Rare Association Between Pernicious Anemia and Neurogenic Bladder - A Case Report and Literature Review
}

\author{
LUCAS P.M. APOLÔNIO, ${ }^{1}$ GERALDO B SILVA JUNIOR, ${ }^{1}$ AMANDA M.M. DANTAS, ${ }^{1}$ PASTORA M.A. DUARTE, ${ }^{1}$ \\ SÔNIA L. SILVA, ${ }^{2}$ ELIZABETH F. DAHER ${ }^{1}$
}

\begin{abstract}
Pernicious anemia is the most common cause of vitamin $B_{12}$ deficiency, being characterized by destruction of the gastric mucosa and the presence of auto-antibodies. We describe a rare case of neurogenic bladder associated with pernicious anemia. The neurologic manifestations (muscular weakness) were partially reversed with vitamin $B_{12}$ replacement, but the vesical symptoms persisted. It is important to investigate the presence of vitamin $B_{12}$ deficiency in cases of neurogenic bladder.
\end{abstract}

Keywords: Anemia; Pernicious anemia; Megaloblastic anemia; Neurogenic bladder; Complications; Vitamin $B_{12}$.

\section{Introduction}

Vitamin $B_{12}$ (cobalamin) deficiency frequently occurs in elderly patients, but it is not always investigated due to its mild manifestations. ${ }^{1}$ All physicians should keep this disease in mind, because it is universaland can cause irreversible neurologic damage, anemia, osteoporosis and cardiovascular diseases. $^{2-10}$

Pernicious anemia is the most common cause of vitamin $\mathrm{B}_{12}$ deficiency, and it is also called Biermer disease, an autoimmune disease characterized by destruction of gastric mucosa and by the presence of auto-antibodies, anti-intrinsic factor and anti-gastric parietal cell ${ }^{1,},{ }^{11-13}$

Patients with neurogenic bladder are at increased risk for numerous complications, such as hydronephrosis, vesicoureteral reflux, renal failure, urinary tract infections, renal stones, bladder cancer, sexual dysfunction and uretral deformities. $^{14}$

\section{Case Report}

A 70 years-old woman was admitted with oliguria since 60 days. She referred dysuria, pelvic pain, abdominal tenderness, urinary incontinence and lower limbs decreased sensitivity. The disease progressed with paraplegy and reduction in the sense of taste and smell. She had a previous diagnosis of rheumatoid arthritis, with important articular deformities (Figure 1), and she was not taking specific medications for this problem.

At physical examination she was stable, with preserved consciousness. She had glossitis (Figure 2), total exodonty

1. Federal University of Ceara, Fortaleza, Ceara, Brazil.

2. University of Fortaleza, Brazil

Correspondence: Dr. Geraldo B Silva Junior, Department of Internal Medicine, School of Medicine, Federal University of Ceara, Ceara, Brazil. E-mail: geraldobezerrajr@yahoo.com.br

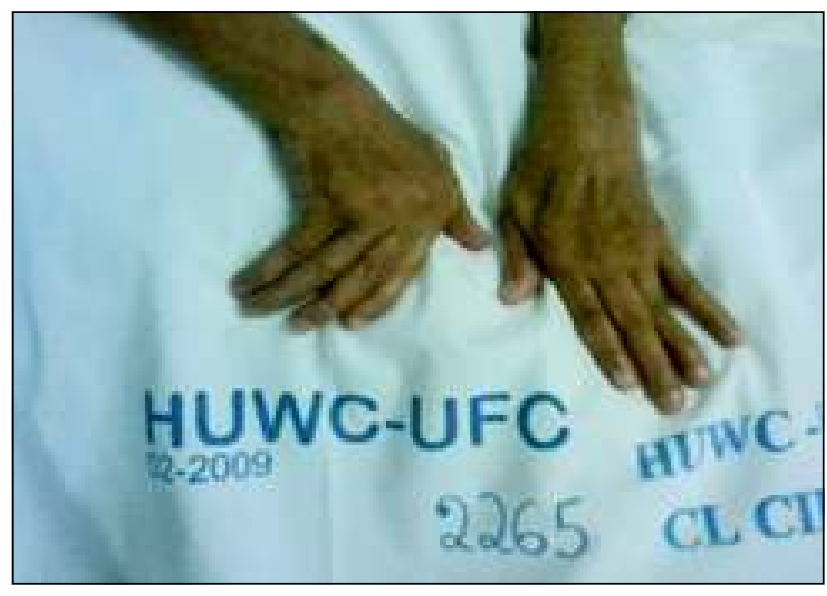

Fig.-1: Rheumatoid arthritis findings - ulnar deviation in both hands and swan neck deformity in left fingers.

and mild lower limbs atrophy. She was using a vesical catheter. The exam of cranial nerves and ophthalmoscopy were normal. Her muscular strength was degree 2 in lower limbs and degree 4 in upper limbs. Tendon reflexes were degree 3 bilaterally, with presence of cutaneo-plantar reflex and positive Hoffmann sign. Thermic, tactile, vibratory and painful sensitivities were decreased to her knees. During hospital stay, the patient presented one episode of urinary tract infection, which was successfully treated with antibiotics.

Laboratory tests at admission evidenced a macrocytic and normochromic anemia ( $\mathrm{Hb} 8.26 \mathrm{~g} / \mathrm{dL}, \mathrm{MCV} 121 \mathrm{fL}, \mathrm{MCH}$ $45.2 \mathrm{pg}, \mathrm{MCHC} 37.4 \mathrm{~g} / \mathrm{dL}$ ), accentuated decreased vitamin $\mathrm{B}_{12}$ levels $(<100 \mathrm{pg} / \mathrm{mL})$, increased erythrocyte sedimentation rate $(52 \mathrm{~mm})$, positive rheumatoid factor $(46 \mathrm{IU} / \mathrm{mL})$ and normal renal function. An uretero-cystography revealed a flaccid and distended bladder (Figure 2). The diagnosis of neurogenic bladder was then stated. Serologies for syphilis, toxoplasmosis, viral hepatitis, HIV and CMV were all 


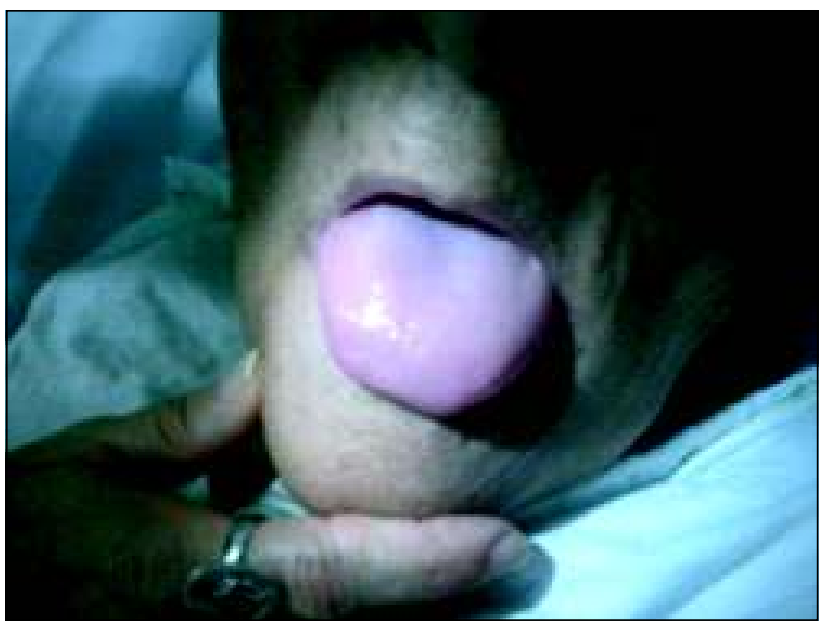

Fig.-2:Glossitis - typical finding of pernicious anemia.

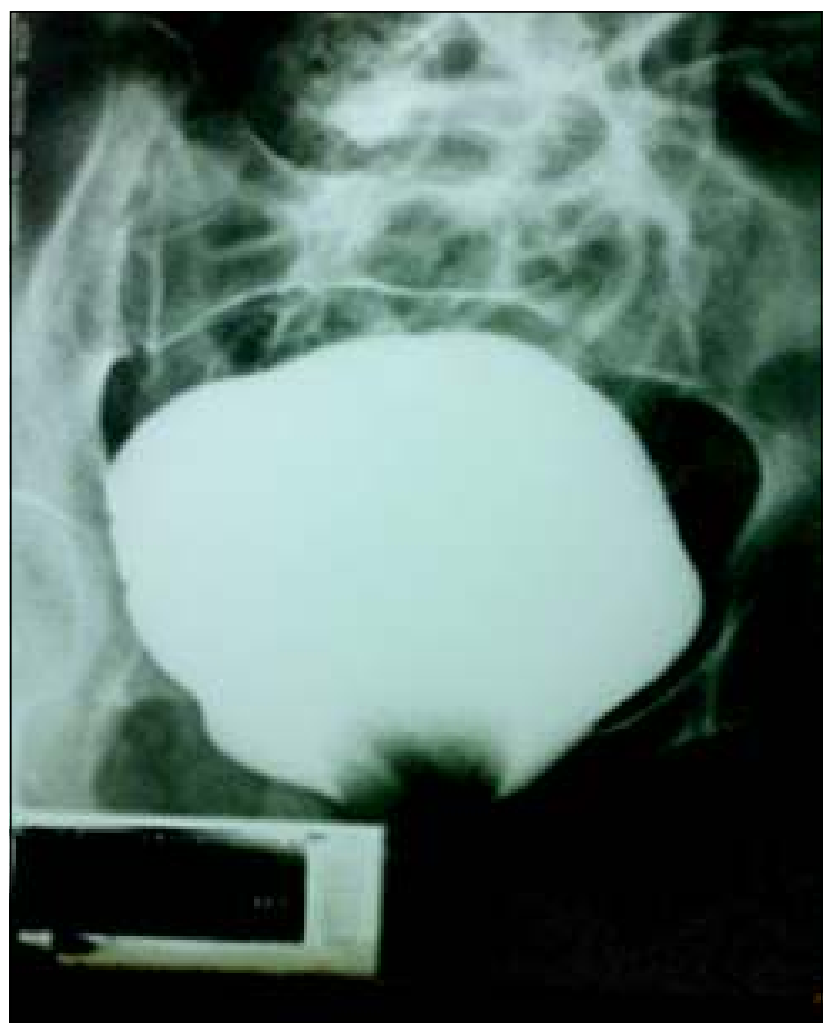

Fig.-3: Urethrocystography evidencing a flacid and distended bladder.

negative. A cervical and thoracic nuclear magnetic resonance was unremarkable, with no signals of medullary compressive factors. Digestive endoscopy evidenced atrophic gastritis (involving the fundus and body) and intestinal metaplasia (involving the antrum). The auto-antibodies (anti-intrinsic factor and anti-parietal cell) were positive.

Treatment with intramuscular vitamin $\mathrm{B}_{12}$ was started with the following regimen: $1000 \mathrm{mcg} /$ day for 7 days, followed by
$1000 \mathrm{mcg} /$ week for 4 weeks and $1000 \mathrm{mcg} / \mathrm{month}$ ad eternum. In the fourth day of hospital stay the patient reported an improvement in sensitivity. In the tenth day, she presented partial recovery of muscular strength in both upper and lower limbs. The neurogenic bladder, however, persisted despite vitamin $\mathrm{B}_{12}$ administration. In the $34^{\text {th }}$ day of hospital stay the patient underwent a supra-pubic cystostomy and was discharged for outpatients' clinics follow-up.

\section{Discussion}

Vitamin $\mathrm{B}_{12}$ (cobalamin) deficiency is a prevalent and underestimated cause of neurologic symptoms. A study developed at Jordan University Hospital ${ }^{3}$ showed a prevalence of vitamin $B_{12}$ deficiency (serum level of cobalamin $<180 \mathrm{pg} / \mathrm{mL}$ ) of $44.6 \%$ in ambulatory patients. Approximately $40 \%$ of patients with cobalamin deficiency exhibit neurological symptoms and signs. ${ }^{20}$ The symptoms diversity varies from frequently reported neurological abnormalities (e.g. peripheral neuropathy, behavioral changes and optic neuropathy) to rarely reported ones (e.g. dementia, urinary incontinence and orthostatic hypotension) ${ }^{9}$

Laboratory confirmation is made with the dosage of cobalamin deficiency biomarkers, such as the red blood cell mean corpuscular volume (MCV), serum cobalamin level, plasma holotranscobalamin, serum methylmalonic acid (MMA) levels and serum homocysteine levels. ${ }^{10}$ In the present case we assessed the MCV and serum cobalamin level, which were compatible with megaloblastic anemia. The other markers were not available in our biochemical analysis laboratory.

There are many causes of vitamin $B_{12}$ deficiency. Insufficient dietary intake in vegan subjects, ${ }^{21}$ non-digestion of food by the lack of enzymes and chloric acid in post-gastrectomy patients ${ }^{22}$ and cobalamin metabolism error (e.g cobalamin-c defect) in newborns ${ }^{23}$ are some clinical scenarios which can precipitate the symptoms. According to a French research group (CARE B12), in elderly patients, such as ours, cobalamin deficiency is caused primarily due to foodcobalamin malabsorption (60-70\%) and pernicious anemia $(15-20 \%){ }^{1}$

Pernicious anemia (PA), first described by Thomas Addison in $1849^{11,13}$, is an autoimmune atrophic gastritis inducing vitamin B12 deficiency. ${ }^{12}$ Chronic atrophic gastritis is recognized macroscopically by the loss of mucosal folds and thinning of the gastric mucosa. Type A (autoimmune) gastritis involves the fundus and body of the stomach and spares the antrum, whereas type $\mathrm{B}$ (non-autoimmune) gastritis involves the antrum as well as the fundus and body. ${ }^{11}$ In the present case, we reported a type A gastritis. This macroscopic 
pathological finding is compatible with an autoimmune character of the disease. The serum inhibitor of intrinsic factor (later found to be an autoantibody to intrinsic factor, IFA) and of autoantibodies to parietal cells (PCA) laid the foundation for the immunologic explanation of the underlying gastritis that causes pernicious anemia. ${ }^{11}$ The reported patient presented both antibodies (anti-intrinsic factor and anti-parietal cell). A survey developed in Italy with 165 patients concluded that combining IFA and PCA testing significantly increases their diagnostic performance of atrophic body gastritis and pernicious anemia, yelding a $73 \%$ sensitivity for PA. ${ }^{24}$

The present case report shows an uncommon association between pernicious anemia and neurogenic bladder. A patient with symptoms of or proven dysfunction of the lower urinary tract and neurological findings (or a neurological disorder) is said to have a neurogenic bladder. ${ }^{18}$ In our literature review, this association has been described before in only two occasions ${ }^{16,17}$ and the reversibility of the neurogenic bladder with specific anemia treatment does not follow a regular pattern.

The most common neurological presentation of vitamin $\mathrm{B}_{12}$ deficiency is sub-acute combined degeneration (SCD) with typical involvement of the posterior and lateral columns of the spinal cord. ${ }^{15}$ A functional radiologic clinical study developed in India ${ }^{17}$ showed that $29.6 \%$ of patients with SCD had symptoms pertaining to voiding or storage symptoms or both. The authors concluded that urodynamic study revealed neurogenic detrusor overactivity with high pressure voiding and detrusor areflexia which improve on vitamin $B_{12}$ therapy. ${ }^{17}$

A possible explanation for the vesical manifestations observed in the present case could be caused by the untreated rheumatoid arthritis. The patient could have had an osteophyte compressing the madullary nerves, but the magnetic resonance discarded this hypothesis. There is no report in medical literature showing the association between rheumatoid arthritis and neurogenic bladder, so the possible cause for the vesical complication seen in our patient remains the pernicious anemia.

Regarding the performance of cystostomy in the present case, despite the better prognosis of doing intermittent vesical catheterization, ${ }^{18}$ we decided to do the surgical procedure because of the social conditions of the patient and the articular deformities, which would difficult the self-catheterization.

Analysing the administration route of vitamin $\mathrm{B}_{12}$ in our literature review, all case-reports used cobalamin intramuscular in an almost standardized dose (1000 ìg daily for 7 days, followed by 1000 ig weekly for 3 weeks and 1000 ìg monthly thereafter) ${ }^{15}$ with little differences. Nevertheless, some recent evidences are favorable to oral vitamin $\mathrm{B}_{12}$ replacement. ${ }^{22,25} \mathrm{~A}$ systematic review suggest that $2000 \mathrm{ig}$ dose of oral vitamin $\mathrm{B}_{12}$ daily and 1000 ig doses initially daily and thereafter weekly and then monthly may be as effective as intramuscular administration. ${ }^{25}$ A more recent South-Korean study involving post-total gastrectomized patients due to gastric cancer concluded that oral cobalamin replacement is an effective and safe treatment. ${ }^{22}$

\section{Conclusion:}

In summary, we reported a rare case of association between pernicious anemia and neurogenic bladder. The causal relationship between these two conditions could be raised because the positive auto-antibodies (IFA and PCA), the endoscopic findings (type A atrophic gastritis) and the absence untreatable clinic condition which could lead to bladder complications The neurologic manifestations (muscular weakness) were partially reversed with vitamin $\mathrm{B}_{12}$ replacement, but the vesical symptoms persisted. It is important to investigate the presence of vitamin $B_{12}$ deficiency in cases of neurogenic bladder of obscure origin.

\section{Conflict of Interest : None}

\section{References}

1. Andrès E, Loukili NH, Noel E, Kaltenbach G, Abdelgheni MB, Perrin AE, Noblet-Dick M, Maloisel F, Schlienger JL, Blicklé JF. Vitamin B12 (cobalamin) deficiency in elderly patients. Can Med Assoc J 2004; 171: 251-259.

2. Iwanami H, Tanaka M, Iwakawa H, Takiguti $Y$, Inukai T. A case presenting with ataxic gait and dementia due to vitamin B12 deficiency without megaloblastic anemia or subacute combined degeneration of the spinal cord. Brain Nerve 2011; 63: 267-269.

3. Barghouti FF, Younes NA, Halaseh LJ, Said TT, Ghraiz SM. High frequency of low serum levels of vitamin 12 among patients attending Jordan University Hospital. East Mediterr Health J 2009; 15: 853-860.

4. Pontes HA, Neto NC, Ferreira KB, Fonseca FP, Vallinoto GM, Pontes FS, Pinto Ddos S Jr. Oral manifestations of vitamin B12 deficiency: a case report. J Can Dent Assoc 2009; 75: 533-537.

5. El Otmani H, Moutaouakil F, Midafi N, Moudden M, Gam I, Hakim K, Fadel H, Rafai MA, El Moutawakkil B, Slassi I. Cobalamin deficiency: neurological aspects in 27 cases. Rev Neurol (Paris) 2009; 165: 263-267.

6. Malizia RW, Baumann BM, Chansky ME, Kirchhoff MA. Ambulatory dysfunction due to unrecognized pernicious anemia. J Emerg Med 2010; 38: 302-307.

7. Nogales-Gaete J, Jiménez P, García P, Sáez D, Aracena R, González J, Lay-Son L, Tenhamm E, Figueroa T, ChávezA, 
Oelker C, Vega L. Subacute combined degeneration of the spinal cord caused by vitamin B12 deficiency. Report of 11 cases. Rev Med Chil 2004; 132: 1377-1382.

8. Szupieñ E, Ositek B, Pniewski J. Difficulties in the diagnosis in the case of subacute paraplegia in a woman with AddisonBiermer disease. Neurol Neurochir Pol 2004; 38: 431-436.

9. Ahn TB, Cho JW, Jeon BS. Unusual neurological presentations of vitamin B(12) deficiency. Eur J Neurol 2004; 11: 339-341.

10. Chatthanawaree W. Biomarkers of cobalamin (vitamin B12) deficiency and its application. J Nutr Health Aging 2011; 15 : 227-231.

11. Toh BH, van Driel IR, Gleeson PA. Pernicious Anemia. N Engl J Med 1997; 337: 1441-1448.

12. Zittoun J. Biermer's disease.Rev Prat 2001; 51: 1542-1546.

13. Whittingham S, Mackay IR. Autoimmune gastritis: historical antecedents, outstanding discoveries, and unresolved problems. Int Rev Immunol 2005; 24: 1-29.

14. Gormley EA. Urologic complications of the neurogenic bladder.Urol Clin N Am 2010; 37: 601-607.

15. Puntambekar P, Basha MM, Zak IT, Madhavan R. Rare sensory and autonomic disturbances associated with vitamin B12 deficiency. J Neurol Sci 2009; 287: 285-287.

16. Campellon JV, Bosley TM, Malloy TR. Neuropathic bladder in setting of severe vitamin B12 deficiency: a case report. J Urol 1995; 154: 199-200.

17. Misra UK, Kalita J, Kumar G, Kapoor R. Bladder dysfunction in subacute combined degeneration: a clinical, MRI and urodynamic study.J Neurol 2008; 255: 1881-1888.
18. Klausner AP, Steers WD. The neurogenic bladder: an update with management strategies for primary care physicians. Med Clin N Am 2011; 95: 111-120.

19. Brocadello F, Levedianos G, Piccione F, Manara R, Pesenti FF. Irreversible subacute sclerotic combined degeneration of the spinal cord in a vegan subject. Nutrition 2007; 23: 622-624.

20. Savage DG, Lindenbaum J. Neurological complications of acquired cobalamin deficiency: clinical aspects. Baillière's Clin Haematol 1995; 8: 657-678.

21. den Elzen WP, van der Weele GM, Gussekloo J, Westendorp RG, Assendelft WJ. Subnormal vitamin B12 concentrations and anaemia in older people: a systematic review. BMC Geriatrics 2010; 10: 42.

22. Kim HI, Hyung WJ, Song KJ, Choi SH, Kim CB, Noh SH. Oral Vitamin B12 Replacement: An Effective Treatment for Vitamin B12Deficiency After Total Gastrectomy in Gastric Cancer Patients.Ann Surg Oncol. 2011 May 10. [Epub ahead of print].

23. Martinelli D, Deodato F, Dionisi-Vici C. Cobalamin C defect: natural history, pathophysiology and treatment. $\mathrm{J}$ Inherit Metab Dis. 2011; 34: 127-35.

24. Lahner E, Norman GL, Severi C, Encabo S, Shums Z, Vannella L, Delle Fave G, Annibale B. Reassessment of intrinsic factor and parietal cell autoantibodies in atrophic gastritis with respect to cobalamin deficiency. Am J Gastroenterol 2009; 104: 2071-2079.

25. Butler CC, Vidal-Alaball J, Cannings-John R, McCaddon A, Hood K, Papaioannou A, Mcdowell I, Goringe A. Oralvitamin B12versusintramuscularvitamin B12 for vitamin B12 deficiency: a systematic review of randomized controlled trials.Fam Pract 2006; 23: 279-285 